\title{
Successful treatment with positive airway pressure ventilation for tension pneumopericardium after pericardiocentesis in a neonate: a case report
}

\author{
Makiko Tani ${ }^{1 *} \mathbb{B}$, Tomoyuki Kanazawa ${ }^{2}$, Naohiro Shioji ${ }^{2}$, Kazuyoshi Shimizu', Tatsuo Iwasaki ${ }^{2}$ and Hiroshi Morimatsu ${ }^{1}$
}

\begin{abstract}
Background: Pneumopericardium in neonates is often associated with respiratory diseases, of which positive pressure ventilation (PPV) is an exacerbating factor. Here, we present a neonate case of pneumopericardium after cardiac surgery which was resolved after applying PPV.

Case presentation: A 28-day-old neonate with left recurrent nerve palsy after aortic reconstruction for interrupted aortic arch developed pericardial effusion. Pericardiocentesis was performed under general anesthesia, and a drainage tube was left in the pericardium. After extubation, stridor gradually exacerbated, following hemodynamic deterioration. A chest X-ray demonstrated pneumopericardium. Upper airway stenosis due to recurrent nerve palsy developed excessive negative pleural pressure, and air was drawn into pericardium via the insertion site of the drainage tube. After tracheal intubation and applying PPV, the pneumopericardium improved.

Conclusion: PPV does not always exacerbate pneumopericardium. In a patient with pericardial-atmosphere communication, increased inspiration effort can cause pneumopericardium, and PPV is a therapeutic option to alleviate the pneumopericardium.
\end{abstract}

Keywords: Pneumopericardium, Pericardiocentesis, Recurrent nerve palsy, Pleural pressure, Positive pressure ventilation

\section{Background}

Pneumopericardium is defined as the collection of air or gas in the pericardium [1]. Pneumopericardium is categorized into two types according to its pathogenesis: spontaneous and traumatic. Spontaneous pneumopericardium in neonates is associated with pulmonary diseases such as hypoplasia and respiratory distress syndrome [2]. Traumatic pneumopericardium occurs by

\footnotetext{
* Correspondence: tani-m1@cc.okayama-u.ac.jp

'Department of Anesthesiology and Resuscitology, Graduate School of Medicine Dentistry and Pharmaceutical Sciences, Okayama University, 2-5-1, Shikata-cho, Kita-ku, Okayama 700-8558, Japan

Full list of author information is available at the end of the article
}

pleural-pericardial communication associated with chest trauma and iatrogenic chest injury. Mechanism of pneumopericardium is presence of direct communication between the pericardium and airways. In addition, pericardium has relatively more negative pressure than intrapleural pressure [3]. Hence, in both spontaneous and traumatic pneumopericardium, PPV could be an exacerbating factor and should be avoided once pneumopericardium is diagnosed [4-6].

When clinically categorized, pneumopericardium is divided into nontension and tension. Tension pneumopericardium leads to hemodynamic collapse which should be treated immediately [7]. Pneumopericardium

\section{Springer Open}

() The Author(s). 2020 Open Access This article is licensed under a Creative Commons Attribution 4.0 International License, which permits use, sharing, adaptation, distribution and reproduction in any medium or format, as long as you give appropriate credit to the original author(s) and the source, provide a link to the Creative Commons licence, and indicate if changes were made. The images or other third party material in this article are included in the article's Creative Commons licence, unless indicated otherwise in a credit line to the material. If material is not included in the article's Creative Commons licence and your intended use is not permitted by statutory regulation or exceeds the permitted use, you will need to obtain permission directly from the copyright holder. To view a copy of this licence, visit http://creativecommons.org/licenses/by/4.0/. 
resulting in cardiac tamponade had been reported to receive PPV [1]. This is also the reason that PPV for patient with pneumopericardium is avoided.

Here, we present a 28-day-old neonate undergoing pericardiocentesis in sub-acute phase after aortic arch anastomosis who developed cardiac tamponade secondary to tension pneumopericardium under spontaneous breathing. Unlike usual pneumopericardium in neonates, the pneumopericardium in this patient exacerbated with increasing spontaneous inspiratory effort due to upper airway stenosis. We ceased spontaneous breathing and successfully treated the tension pneumopericardium by tracheal intubation and PPV.

\section{Case presentation}

This patient was a 28-day-old female neonate born at gestational age of 39 weeks with no prenatal diagnosis. The neonate was diagnosed as having interrupted aortic arch (IAA) type B, patent ductus arteriosus (PDA), ventricular septal defect (VSD), and atrial septal defect. At 13-days old, this neonate underwent aortic arch reconstruction by extended aortic arch anastomosis, PDA ligation, and VSD patch closure under general anesthesia using $3.5 \mathrm{~mm}$ of uncuffed endotracheal tube (ETT). Immediately after the extubation on postoperative day (POD) 2, the patient presented hoarseness and severe stridor that were diagnosed as left recurrent nerve palsy by an otolaryngologist with fiberoptic examination of the vocal cords. Although stridor occurred when asleep, the patient was uneventfully discharged from the intensive care unit (ICU) on POD4 without any respiratory support. On POD 15, elective pericardiocentesis in the operating room (OR) was scheduled for increasing pericardial effusion. Pericardiocentesis was performed uneventfully by epigastric approach under general anesthesia with tracheal intubation. Ten milliliters of serosanguineous fluid was drained, and a silicon drainage tube was left in the pericardium. The tube was connected to a drainage system applying negative pressure of $8 \mathrm{cmH}_{2} \mathrm{O}$. After confirming no pneumothorax or pneumopericardium on chest X-ray (Fig. 1a), the patient was extubated in the OR and was transferred to the ICU. The clinical course of this patient after admission to the ICU is shown on Fig. 2.

In the ICU, the patient presented with tachypnea, tachycardia, hypertension, and stridor, and was given
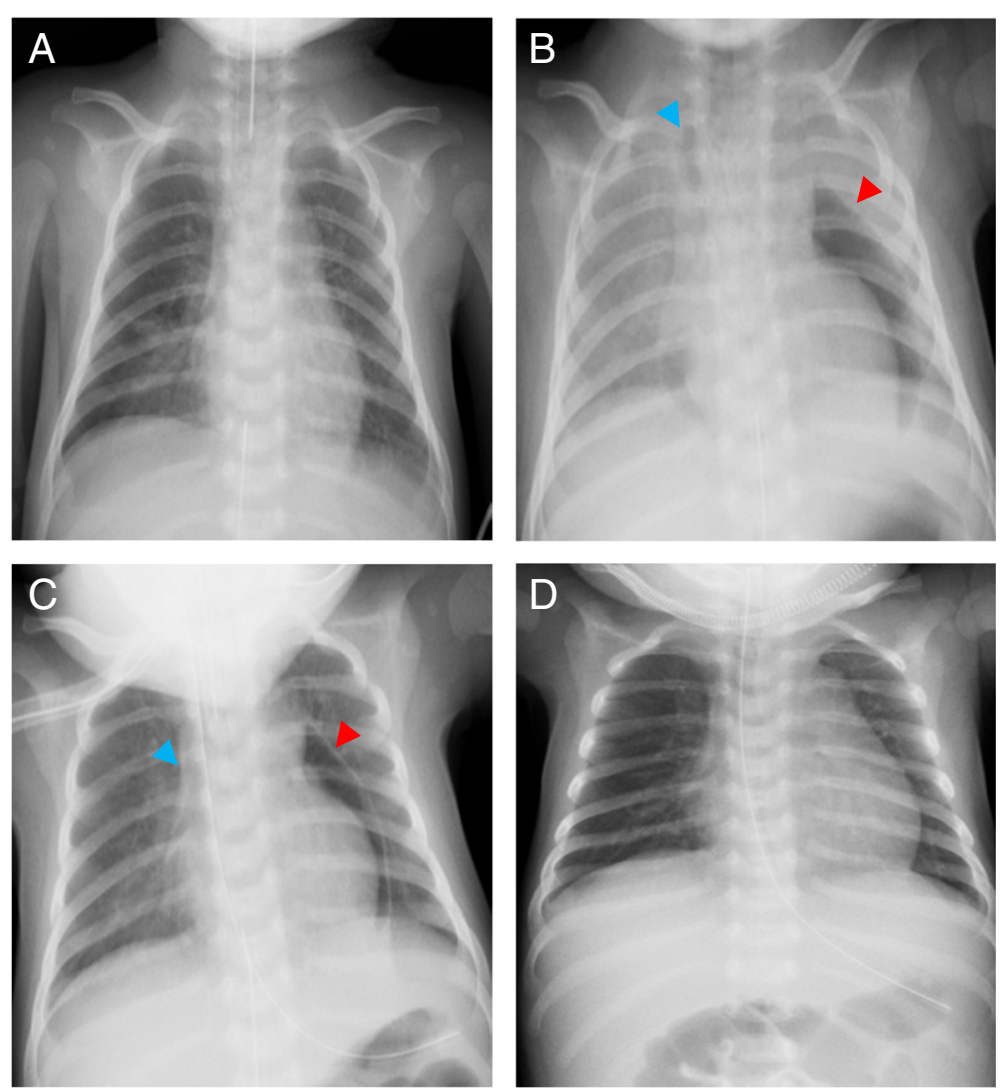

Fig. 1 Chest $X$-rays in the operating room and in the intensive care unit. a Right after the pericardiocentesis, $\mathbf{b}$ before re-intubation approximately $2.5 \mathrm{~h}$ after admission to the ICU, c 10 min after re-intubation, and $\mathbf{d}$ after the drainage tube was removed. The red and blue arrows indicate pneumopericardium and pneumomediastinum, respectively 


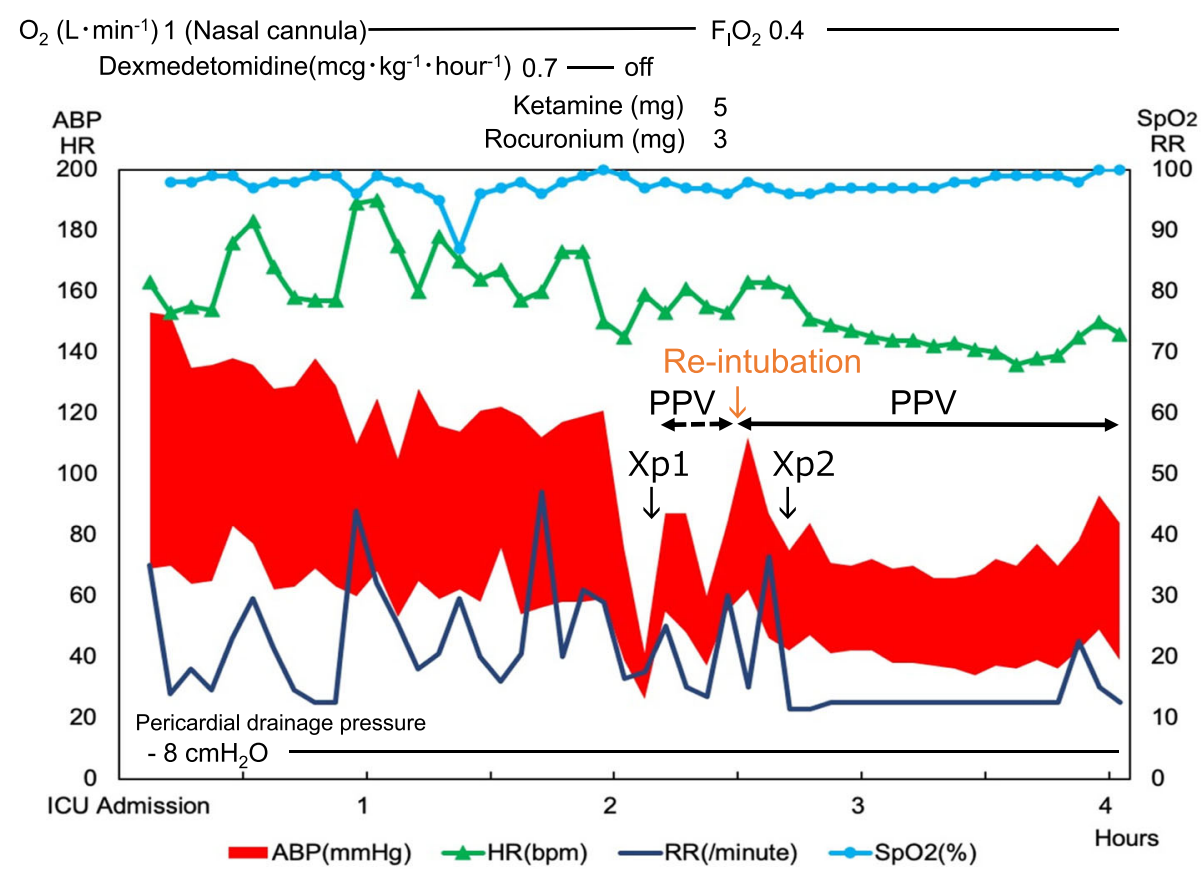

Fig. 2 Clinical course in the intensive care unit. $\mathrm{O}_{2}$, oxygen; $\mathrm{F}_{1} \mathrm{O}_{2}$, fraction of inspiratory oxygen; $A B P$, arterial blood pressure; $H R$, heart rate; bpm, beats per minute; $\mathrm{RR}$, respiratory rate; $\mathrm{SpO}_{2}$, peripheral oxygen saturation; PPV, positive pressure ventilation. The chest $\mathrm{X}$-rays of Fig. $1 \mathrm{~b}$ and $\mathrm{c}$ were taken at the time shown as Xp1 and Xp2, respectively, in this chart

acetaminophen for analgesia. The acetaminophen was not effective, and the patient was administered $0.7 \mathrm{mcg}$

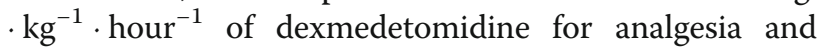
sedation in the hope of decreasing work of breathing. However, the stridor deteriorated, and retraction developed. In addition, systolic arterial blood pressure (sABP) dropped to $40 \mathrm{mmHg}$ in $15 \mathrm{~min}$ although the heart rate was kept over 140 beats per minute. Because of new onset of mandibular breathing in addition to progressive hypotension, we stopped dexmedetomidine infusion and started bag-valve-mask ventilation $2 \mathrm{~h}$ after admission to the ICU. After starting positive pressure ventilation, blood pressure slightly increased. A chest X-ray revealed pneumopericardium and pneumomediastinum without pneumothorax (Fig. 1b). The cause of the hemodynamic deterioration was thought to be developing cardiac tamponade secondary to tension pneumopericardium. Inspection of the drainage system showed no loose connection which could suck air into the pericardium through the drainage tube or obstruction by blood, clots, and bending. In addition, we confirmed that excessive negative pleural pressure was generated because negative pressure alarm in the drainage system sounded and the drainage fluid was about to draw into the pericardial space. As a result, we concluded that (1) inspiratory effort by upper airway stenosis due to the existing left recurrent nerve palsy was exacerbated by glossoptosis induced by sedation and that (2) negative pleural pressure augmented by the increased inspiratory effort caused air suction into pericardium via insertion route of a drainage tube. The patient was intubated and was placed on mechanical ventilation. Eventually, sABP became stable to $70 \mathrm{mmHg}$, and pneumopericardium decreased on the chest X-ray (Fig. 1c). Two days later, confirming no remaining pneumopericardium or adverse events, the drainage tube was removed, and the patient was extubated again (Fig. 1d). The patient used high flow nasal cannula for 1 day in the ICU and spent an additional 6 days in the ward with no recurrent pericardial effusion or pneumopericardium before being discharged from the hospital.

\section{Discussion}

This is a case in which pneumopericardium after pericardiocentesis developed by excessive negative pleural pressure due to upper airway stenosis. The cause of the pneumopericardium and the reason that PPV was effective are discussed below.

In this case, pneumopericardium resulting in cardiac tamponade was successfully treated by PPV. Cummings et al. reported that over $60 \%$ of causes of pneumopericardium leading to cardiac tamponade were chest trauma and diseases in lung-pleura [1]. And, PPV is one of the reasons for hemodynamic collapse. Thus, it was critical to diagnose the cause of the pneumopericardium in the patient to justify PPV for improving hemodynamic 
deterioration. This patient did not have any lung disease. In addition, neither pneumothorax nor pneumopericardium were confirmed in the chest X-ray during PPV in the OR. These findings suggested this pneumopericardium occurred by some causes which happened after extubation. Pneumopericardium after pericardiocentesis was reported to occur by pleural-pericardial communication [8-10]. However, no air in the pleural space or loose connection in the drainage was found. Absence of air in the pleural space with existence of pneumopericardium under negative pressure ventilation indicated that there was no pleural-pericardial communication. Eventually, we diagnosed that the cause of pneumopericardium was the negative pressure applied to the pericardium which exceeded drainage suction pressure and that air was sucked through the slit between the skin and the pericardium drainage tube.

Another distinctive feature in this case is the reason for excessive negative intra-pericardial pressure. First, increasing inspiratory effort by upper airway stenosis produced markedly negative pleural pressure. The patient had left recurrent nerve palsy as a complication after repair of aortic arch anastomosis for IAA (type B). It was reported that vocal cord palsy occurred in $47.2 \%$ of infants after aortic arch augmentation for IAA or hypoplastic aortic arch [11]. In addition to the recurrent nerve palsy, glossoptosis induced by sedation aggravated upper airway stenosis. The negative airway pressure elicited airway deformity, and triggered ventilatory overshoot [12], which exacerbated negative pleural pressure. Because the pericardium is contiguous with pleural space, the negative pleural pressure was propagated to the pericardium.

A previous case report presented pneumopericardium by leaky drainage system [10]. However, there was no loose connection in the pericardium drainage system, and $-8 \mathrm{cmH}_{2} \mathrm{O}$ was applied to the system in this case. Negative airway pressure accompanied by obstructive upper airway has been reported to exceed $-50 \mathrm{cmH}_{2} \mathrm{O}$ $[13,14]$. The vacuum pressure of the drainage was much less than negative pleural pressure in this patient and was not effective to evacuate the air that was drawn from the atmosphere.

PPV had two effects in this case: (1) positive pressure was propagated to the pericardium and stopped the sucking of air into the pericardium from the slit between the skin and the drainage tube and (2) air in the pericardium was drained into the drainage bottle because the pericardial pressure was relatively positive compared with the pressure applied to the drainage bottle.

There is a limitation in our approach to this pneumopericardium. We diagnosed this patient as cardiac tamponade just by clinical symptoms and chest X-ray. We should have performed echocardiogram to confirm the diagnosis and to assess effectiveness of the therapeutic intervention.

In conclusion, positive airway pressure is not always an exacerbating factor of pneumopericardium. In a patient with pericardial-atmosphere communication, increased inspiration effort can be a cause of pneumopericardium, resulting in cardiac tamponade, and PPV is a therapeutic option to alleviate the pneumopericardium.

\begin{abstract}
Abbreviations
PPV: Positive pressure ventilation; IAA: Interrupted aortic arch; PDA: Patent ductus arteriosus; VSD: Ventricular septal defect; ETT: Endotracheal tube; POD: Postoperative day; ICU: Intensive care unit; OR: Operating room; sABP: Systolic arterial blood pressure; $\mathrm{O}_{2}$ : Oxygen; $\mathrm{F}_{1} \mathrm{O}_{2}$ : Fraction of inspiratory oxygen; ABP: Arterial blood pressure; HR: Heart rate; bpm: Beats per minute; RR: Respiratory rate; $\mathrm{SpO}_{2}$ : Peripheral oxygen saturation
\end{abstract}

Acknowledgements

We would like to thank Ms. Rebecca Lahniche for English language editing.

Authors' contributions

MT reviewed the literature and elaborated on the manuscript. TK and NS helped in the conception of the article and provided critical revisions. KS, TI and HM provided critical revision. The authors read and approved the final manuscript.

\section{Funding}

Not applicable.

Availability of data and materials

Not applicable due to patient privacy concerns.

Ethics approval and consent to participate

Not applicable

Consent for publication

Parents of the patient have provided written consent to publish this case.

Competing interests

The authors declare that they have no competing interests.

\section{Author details}

${ }^{1}$ Department of Anesthesiology and Resuscitology, Graduate School of Medicine Dentistry and Pharmaceutical Sciences, Okayama University, 2-5-1, Shikata-cho, Kita-ku, Okayama 700-8558, Japan. ${ }^{2}$ Department of Anesthesiology and Resuscitology, Okayama University Hospital, 2-5-1, Shikata-cho, Kita-ku, Okayama 700-8558, Japan.

Received: 20 September 2020 Revised: 27 September 2020 Accepted: 29 September 2020 Published online: 07 October 2020

\section{References}

1. Cummings RG, Wesly RL, Adams DH, Lowe JE. Pneumopericardium resulting in cardiac tamponade. Ann Thorac Surg. 1984;37:511-8.

2. Papoff P. MC. Pulmonary air leakage. Neonatology. Milano: Springer; 2012. p. 460-468.

3. Lansdorp B, Hofhuizen C, van Lavieren M, van Swieten H, Lemson J, van Putten MJ, et al. Mechanical ventilation-induced intrathoracic pressure distribution and heart-lung interactions*. Crit Care Med. 2014;42:1983-90.

4. Varano LA, Maisels MJ. Pneumopericardium in the newborn: diagnosis and pathogenesis. Pediatrics. 1974;53:941-5.

5. Macklin CC. Transport of air along sheaths of pulmonic blood vessels from alveoli to mediastinum: clinical implications. Arch Intern Med. 1939:64:913-26.

6. Mansfield PB, Graham CB, Beckwith JB, Hall DG, Sauvage LR. Pneumopericardium and pneumomediastinum in infants and children. J Pediatr Surg. 1973;8:691-9. 
7. Bonardi CM, Spadini S, Fazio PC, Galiazzo M, Voltan E, Coscini N, et al. Nontraumatic tension pneumopericardium in nonventilated pediatric patients: a review. J Card Surg. 2019;34:829-36.

8. Mullens W, Dupont M, De Raedt H. Pneumopericardium after pericardiocentesis. Int J Cardiol. 2007;118:e57.

9. Choi WH, Hwang YM, Park MY, Lee SJ, Lee HY, Kim SW, et al.

Pneumopericardium as a complication of pericardiocentesis. Korean Circ J. 2011:41:280-2.

10. Cho SH, Hwang HJ, Park CB. Pneumopericardium after pericardiostomy. J Formos Med Assoc. 2016;115:816-7.

11. Lee MGY, Millar J, Rose E, Jones A, Wood D, Luitingh TL, et al. Laryngeal ultrasound detects a high incidence of vocal cord paresis after aortic arch repair in neonates and young children. J Thorac Cardiovasc Surg. 2018;155: 2579-87.

12. Harms CA, Zeng YJ, Smith CA, Vidruk EH, Dempsey JA. Negative pressureinduced deformation of the upper airway causes central apnea in awake and sleeping dogs. J Appl Physiol. 1996;80:1528-39.

13. Newton-John H. Pulmonary oedema in upper airway obstruction. Lancet. 1977:2:510.

14. Lang $S A$, Duncan $P G$, Shephard DA, Ha HC. Pulmonary oedema associated with airway obstruction. Can J Anaesth. 1990;37:210-8.

\section{Publisher's Note}

Springer Nature remains neutral with regard to jurisdictional claims in published maps and institutional affiliations.

\section{Submit your manuscript to a SpringerOpen ${ }^{\circ}$ journal and benefit from:}

- Convenient online submission

- Rigorous peer review

- Open access: articles freely available online

- High visibility within the field

- Retaining the copyright to your article

Submit your next manuscript at $\boldsymbol{\nabla}$ springeropen.com 